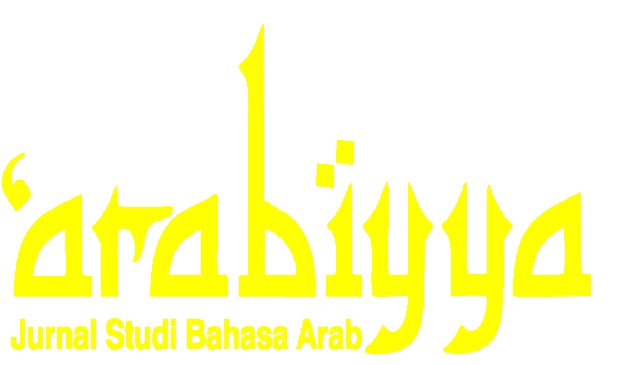

\author{
Arabiyya : Jurnal Studi Bahasa Arab \\ P-ISSN 2338-4964 (Print), E-ISSN 2615-238X (Online) \\ Available online: https://ejournal.staindirundeng.ac.id/index.php/arabiyya
}

\title{
تطوير مواد تعليم اللغة العربية في ضوء المنهج على مستوى الوحدة التعليمية \\ (KTSP)
}

\author{
Wahyu Mimbar \\ Email: wahyumimbar4578@gmail.com \\ STAI Darul Hikmah Aceh Barat
}

\begin{abstract}
Babul Maghfirah Is one Of junior high Schools located in Aceh Besar which gives high attention to Arabic Learning In This Rase, It is one of 13 Junior high Schools In Aceh Besar which still Implements School-Based Curriculum (KTSP) in Teaching learning process. That is why, the write intended to conduct a Research under the title "The Analysis of Arabic Material in School-Based Curriculum design" The present research was aimed to Find Out : 1) The Obstacle Faced by the Teacher in transferring the material in school-Based Curriculum design, 2) The Strength and weakness Of SchoolBased Curriculum method, and 3) The analysis of Arabic learning from cognitive, effective and Psikomotor view in School-Based Curriculum design. Descriptive Qualitative design was used in this research so that the writer used Questionnaire, Observation, and Interview to collect the data needed. Furthermore, all students (24 students) of grade VIII were become the sample of this research. After Conducting the research, it was Found that : 1) most of the Teachers had lack understanding toward the School-Based Curriculum it self. It was caused by the Curriculum was not a perfect design and still need a futher development: 2) Lack of understanding in "Nahwu and Qawai'id" material was one of the weakness of KTSP in cognitive. It made The Students hard to master the method of giving the line, gathering new vocabularies and expression. Thus, it led them to be unable to speak Arabic, Affectively, the Students were more exsited to learn Arabic with School-Based Curriculum design, in psikomotor aspect, the writer found that students had good Capability in Performing " istima'kalamQira'ah and Khitabah". They also tonded to motivate each other. 3) After Conducting observation, Interview and Questionnare, It was also found that the Material of Arabic Language in School-Based Curriculum did not meet to Students need.
\end{abstract}

Keywords: Analysis, Material in School- Based, KTSP.

\begin{abstract}
Abstrak
SMP Babul Maghfirah salah satu sekolah yang terletak di Aceh Besar, yang mana sekolah tersebut memberi perhatian yang sangat besar terhadap Pembelajaran Bahasa Arab disamping Bahasa Inggris dan lainya, sebagaimana yang Peneliti dapatkan SMP Babul Maghfirah adalah salah satu Sekolah dari 13 Sekolah di Aceh Besar yang masih menggunakan Kurikulum Tingkat Satuan Pembelajaran (KTSP) pada Progress
\end{abstract}


Pengajaran nya, oleh karena itu Peneliti tertarik untuk mengadakan sebuah Penelitian yang berjudul Analisis Materi Bahasa Arab dalam Kerangka KTSP yang bertujuan untuk mengetahui 1) Permasalahan yang dihadapi Guru ketika menyampaikan Materi Bahasa Arab dalam kerangka KTSP 2) Kelebihan dan Kekurangan Metode KTSP 3) Analisi Pembelajaran Bahasa Arab dari Segi Kognitif Afektif dan Psikomotor dalam rangka KTSP adapun Metode Penelitian yang penulis gunakan adalah Metode Deskriptif Kualitatif dalam hal pengambilan data, penulis menggunakan Angket, Observasi, Wawancara, dengan Sampel dari Penelitian ini adalah semua Siswa /i kelas VIII yang berjumlah 24 orang, dari hasil Penelitian diketahui bahwa : 1) Masalah yang dihadapi Guru adalah kurang nya Pemahaman terhadap KTSP dikarenakan Metode KTSP yang belum sempurna yang butuh kepada perbaikan dan Pegembangan, sehingga Materi KTSP lebih Fungsional dan dapat Melahirkan Guru yang bermutu dan Kompeten dalam Bahasa Arab 2) Kelebihan dan Kekurangan KTSP dari Segi Kognitif adalah kurang nya Peguasaan Materi Nahwu dan Qawaid sehingga terkendala dalam memberi baris dan kurang nya Mengusai Kosa Kata baru dan gaya Bahasa sehingga membuat mereka susah dalam berbicara Bahasa Arab, dari segi Afektif adalah Siwa/i sangat bahagia belajar Menggunakan KTSP dari Segi Psikomotor baik dari segi Istima' kalam Qira'ah dan Kitabah sudah bagus keseluruhan nya dan saling memberi Motivasi satu sama lain nya. 3) Analisis Materi Pembelajaran Bahasa Arab Segi Kognitif Afektif dan Psikomotor dalam Rangka KTSP belum memuaskan setelah dilakukan Observasi, Wawancara dan Pembagian Angket dan hipotesis ini diterima.

Kata Kunci : Analisis, Materi Pembelajaran, KTSP

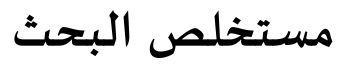

تقع مدرسـة باب المغفرة بمنطقة أتشيه بسار، والطلاب يلزمون أن يستعملون اللغة العربية لشؤون حياتهم اليومية بجانب الإنجليزية في كل أسبوع على السواء، كما لاحظ الباحث إن مدرسة باب المغفرة إحدى مدارس من ثلاث عشرة بمنطقة أتشيه بسار يطبق مواد تعليم اللغة العربية في ضوء المنهج على مستوى الوحدة التعليمية (KTSP) ، ومما الأغراض التي يدفع الباحث إلى كتاب الرسالة هي: لمعرفة 1) المشكلات عند المدرس في القاء مواد التعليم اللغة العربية في ضيوء المنهج على مستوى الوحدة التعليمية بالمدرسة المتو سطة باب المغفرة أتشيه بسار، 2) معرفة مزايا وعيوب تحليل مواد التعليم اللغة العربية في ضوء المنهج على مستوى الوحدة التعليمية بالمدرسة المتو سطة باب المغفرة أتشياه بسار، 3) معرفة تعليم اللغة العربية من ناحية المعرفة والوجدان والنفسحركي في ضوء المنهج على مستوى الوحدة التعليمية بالمدرسـة المتو سطة باب المغفرة. وأما المنهج سلك عليه الباحث في هذه البحث هو المنهج الوصفي تحليلي وأما البيانات التي يحتاج إليها الباحث فتجمعها عن طريقة 
توزيع الإستبانة لطلبة و الملاخظة المباشرة والمقابلة الشخصية مع مدرسي اللغة

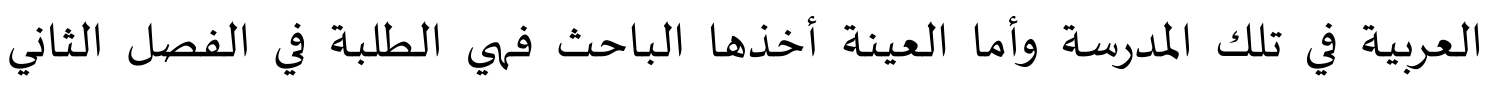
المتوسطة بمدرسة باب المغفرة عددهم 24 طالبا. من نتائج البحث التي وصل إليها

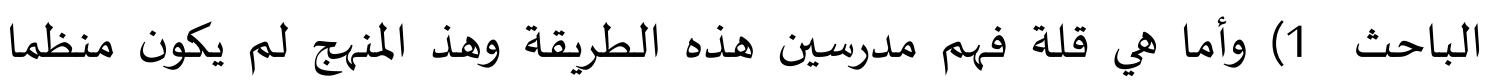
وموادة غير وظيفي. ويحتاج الى المدرس الكفاء باللغة العربية 2) وأما مزهيها وعيوبها

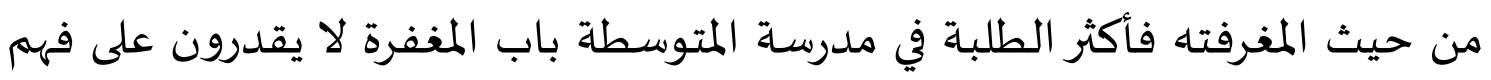

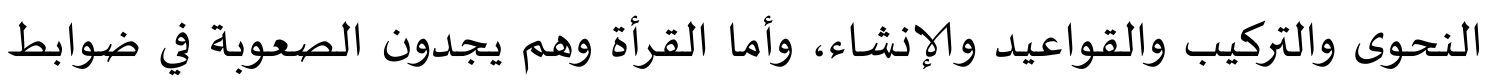
الحروف الآخرة من كلمة وعدم معرفتهم المفردات الجديدة وقلة فهم قواعد في

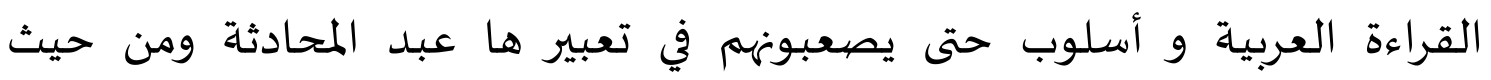

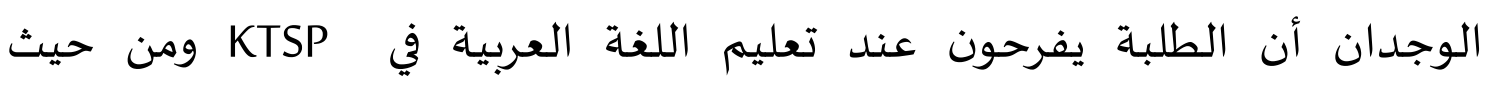

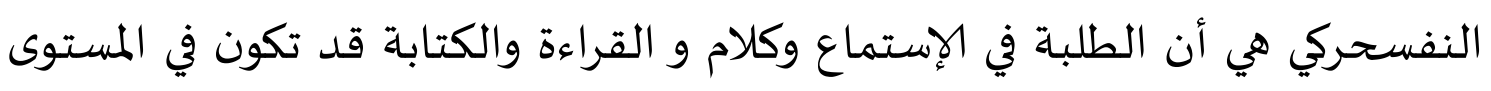

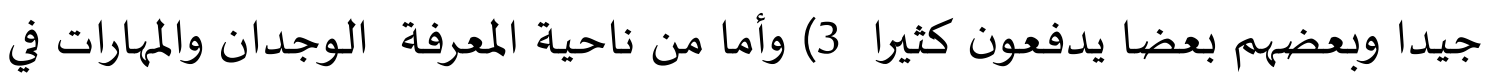

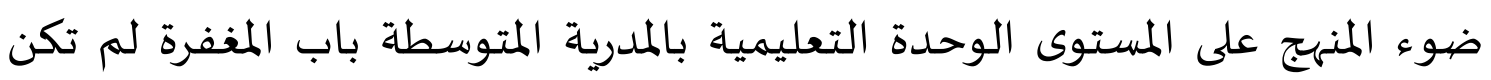

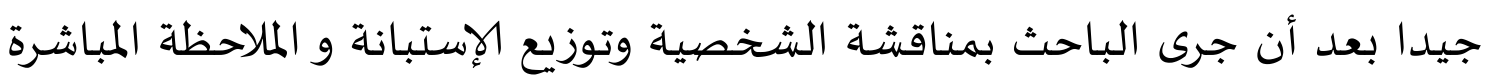

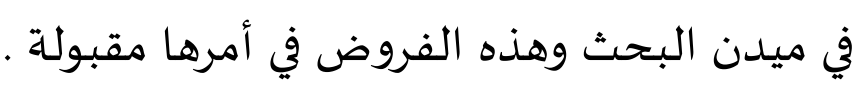

الكلمات المحورية: تحليل، مواد التعليم، المنهج على مستوى الوحدة التعليمية

أ. المقدمة

تعد اللغة أعظم الآلات التى يستخدمها الإنسان فى تحقيق التعاون والاتصال

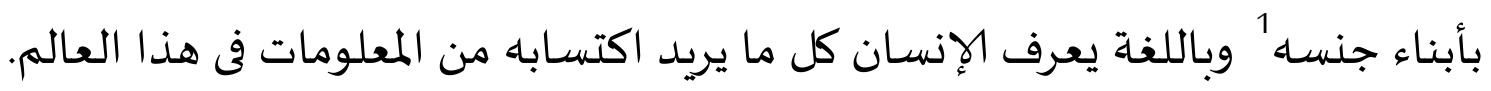

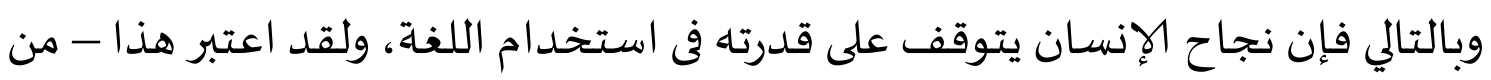

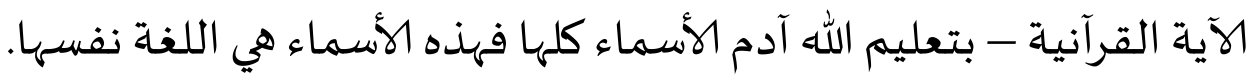

12 دحية مسقان، استراتيجية تعليم اللغة العربية الفعال للناطقين بغيرها قراءة فى تجربة معهد دار

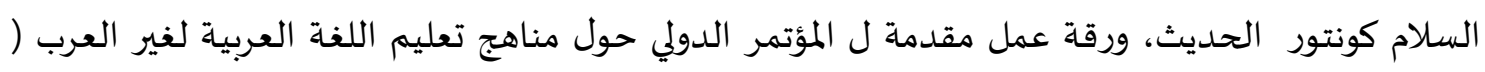

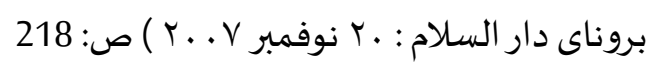

211 | Wahyu Mimbar:..... تطوير مواد تعليم اللغة العربية 
ومما سبق يتضح أن اللغة إنما هي وسيلة لا غاية لذاتها فهي أداة الفرد للتفكير

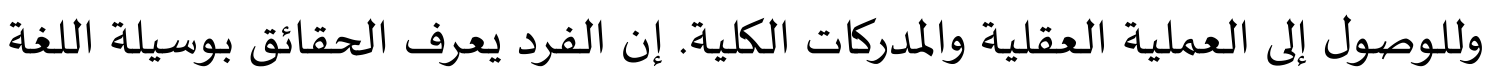
التى يستخدمها بأبناء جنسـه. وعلى ضوء تعليم اللغة العربية أن هذه اللغة هي وسيلة إنها

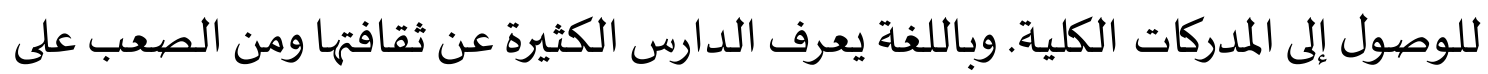
دارس اللغة كلغة ثانية أن يفهمها جيدا أو يستخدمها استخداما صحيحا دون أن يفهم

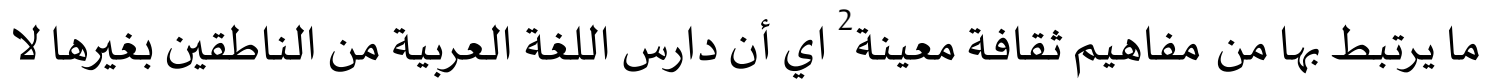

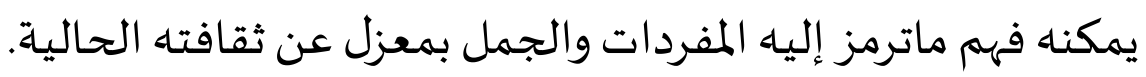

وعلى ضوء تعليم اللغة أيضا أن تبدو ضرورة وجود أهمية الكتاب المدرسي أمرا لايحتاج إلى تقرير، ويبقى للكتاب المدرسي مكانته المنفردة فى العملية التعليمية مادام

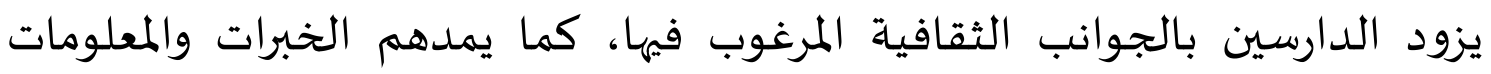

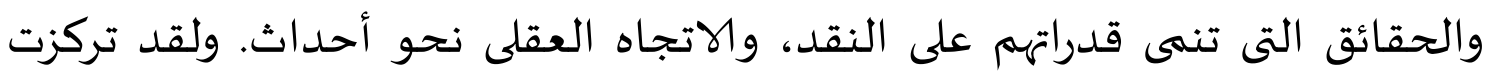

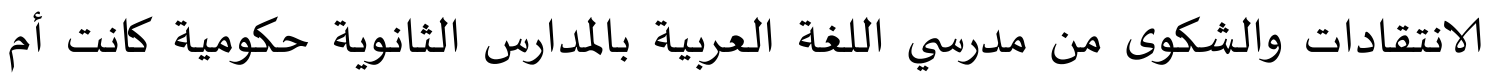

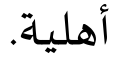

وهناك كثير من الأبعاد المتعلقة بالألفاظ وبالتراكيب التى لن يعلم الدارس دون

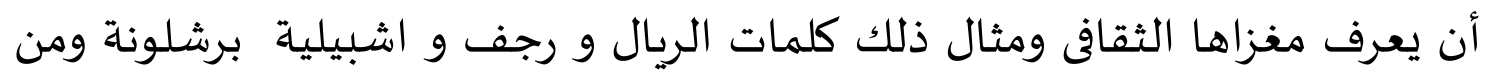

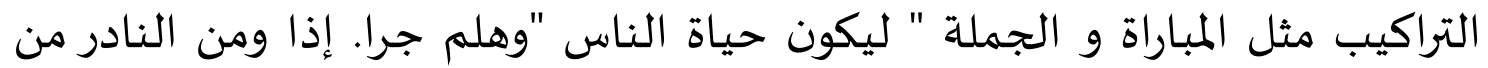

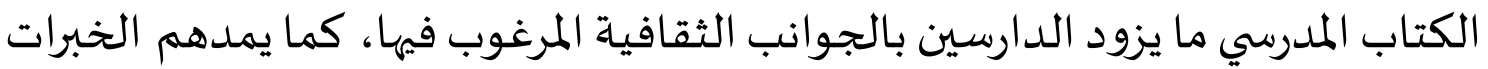
والمعلومات والحقائق التى تنهى قدراتهم على النقد، والاتجاه العقلى نحو أحداثه.

ب. منهج البحث

وأما المنهجية التي يستخدم عليها الباحث في كتابة هذه الرسالة منهجا

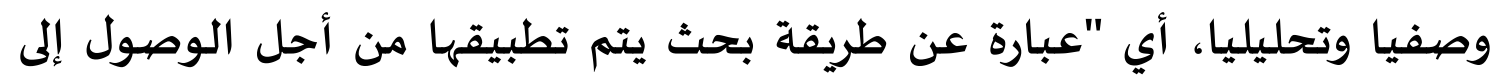

22 رشيد يوسف محمد عباس، الإطار العملي لبرامج تعليم اللغة العربية للناطقين بغيرها من اللغات

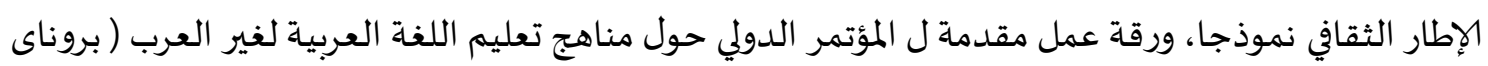

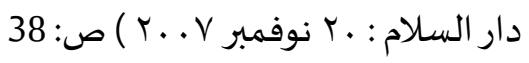


وصف كمي هادف ومنظم لمحتوى أسلوب الإتصال". ${ }^{3}$ وأما جمع البيانات والمعلومات التي يحتاج إلهها الباحث يكون عن طريقين: طريقة البحث المكتبي

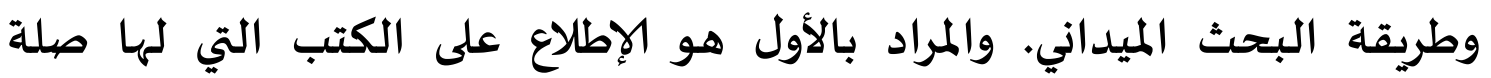

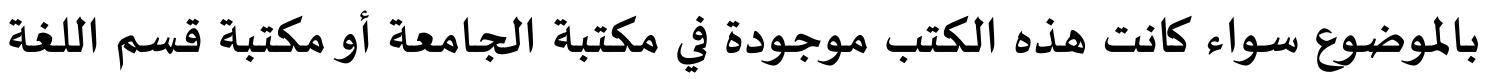

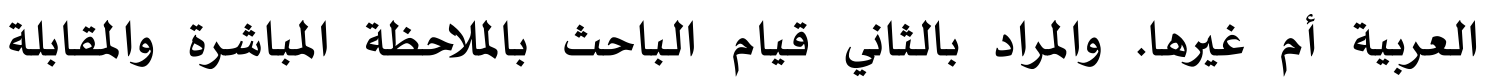
الشخصية وتوثيق.

وأما ادوات البحث المستخدمة لجمع البيانات فيعتمد الباحث على الأدوات التالية:

1- وثيقة أسئلة اللغة العربية : وهي أسئلة اللغة العربية التي وضعها مدرسو

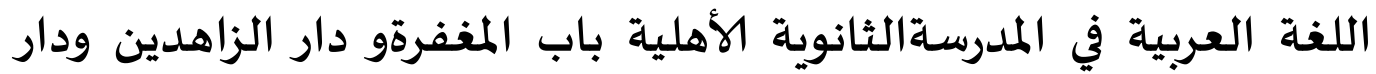
العمل. 2- المقابلة الشخصية مع المدرسي اللغة العربية في المدرسـالثانوية الأهلية باب المغفرةو دار الزاهدين ودار العمل لمعرفة الأحوال التعليمية في تلك الك المديه

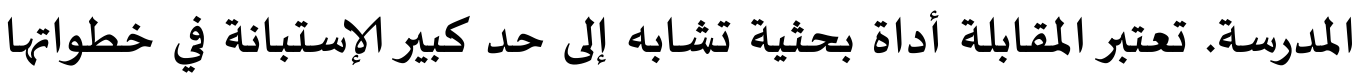
ومواصفاتها مع فارق واحد هو أنها حوار بين الباحث وصياحب الحالة المراد الحصول على معلومات منه أو تعبيراته عن آرائه واتجاهاته ومشاعراعره، ويقوم بالمقابلة أشخاص مدربون تدريبا خاصيا لجمع البيانات من الأفراد

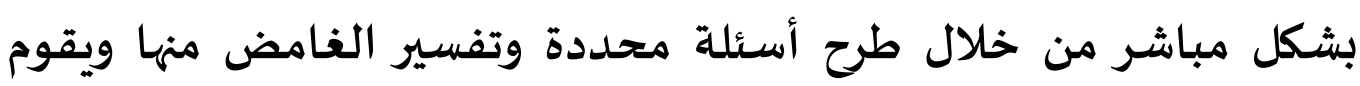
الباحث أو من ينوب عنه بتسبجيل ما دار فيها.

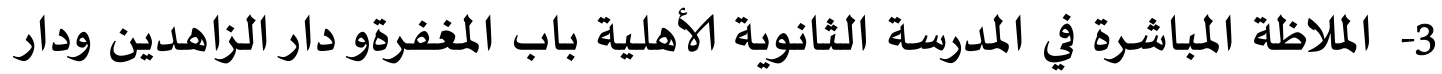

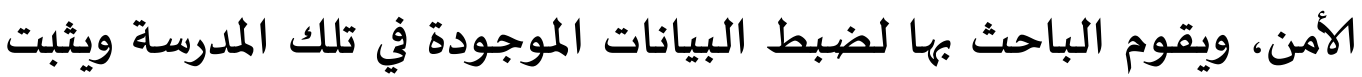
الحصيلة الميدنية. تعد الملاظة من الأدوات البحثية التي يمكن استخدامهيا

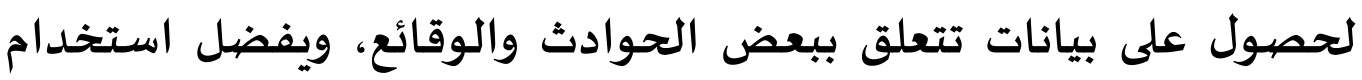

"ُالح بن محمد العاساق، "المدخل إلى البحث في العلوم السلوكية"، الطبعة الثنية( الرياض: مكتبة

$$
\text { العبيكان، 2000)، ص:49. }
$$


الملاحظة كأداة بحثية على غيرها من الأدوات وخاصية عندما تكون ممكنة حيث يتم فيها تحديد ما هو مطلوب التركيز عليه وتدوين ما يراه الباحث أو يسمعه بدقة تامة.

وكان أسلوب تحليل البيانات لهذا البحث المستخدمة برمز النسبة

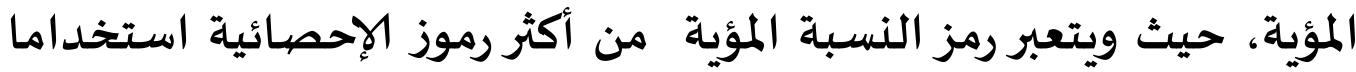

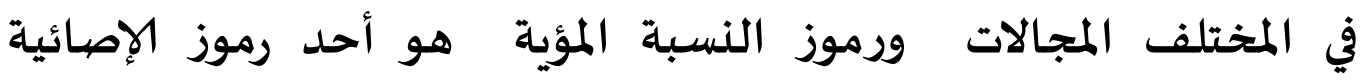

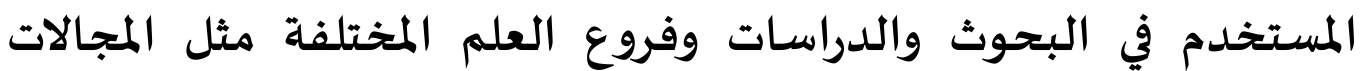
التربوية والفنية والهندسية والزراعية وغيرها. فقام الباحث على ما قال

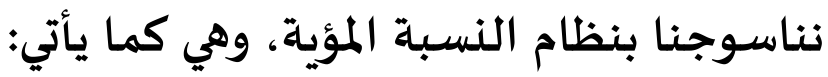

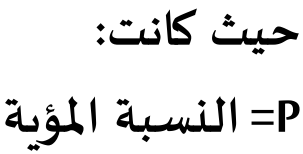

F مجموع من أسئلة اللغة العربية من حيث يقسم إلى المجال المعرفي

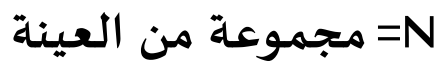

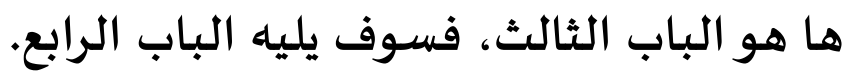

ج. تحليل البيانات قام الباحث في بحث هذه الرسالة بتوزيع الاستبانة على الطللبة للحصول

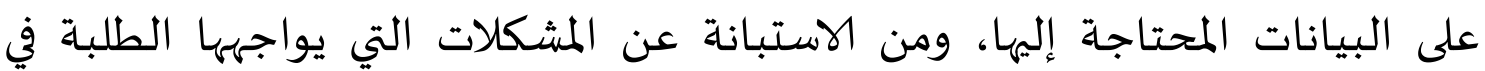
سيطرة تعلم اللغة العربية بالمنهج فضوءوالمنهجعلممستوى الوحدة التعليمية : 


\section{الجدول 4 4}

\begin{tabular}{|c|c|c|c|}
\hline النسبة المأوية & مجموع الأجوبة & احتمال الأجوبة & رقم \\
\hline$\% 28.57$ & 6 & أرغب جدا & أ \\
\hline$\% 61 ، 90$ & 13 & أرغب قليلا & ب \\
\hline$\% 9.52$ & 2 & لا أرغب & ج \\
\hline$\% 100$ & 21 & المجموع & \\
\hline
\end{tabular}

والجدول السابق يدل أن 28،57\% من الطلبة يرغبون جدا في تعلم اللغة

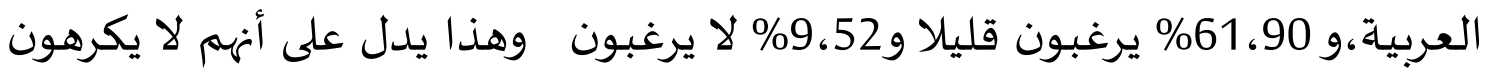

في تعلم اللغة العربية وهم يرغبون فيها.

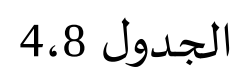

\begin{tabular}{|c|c|c|c|}
\hline النسبة المأوية & مجموع الأجوبة & احتمال الأجوبة & رقم \\
\hline$\% 14.28$ & 3 & يناسب جدا & أ \\
\hline \multirow[t]{2}{*}{$\% 85.71$} & 18 & يناسب قليلا & ب ب \\
\hline & - & لا يناسب & ج \\
\hline$\% 100$ & 21 & المجموع & \\
\hline
\end{tabular}

والجدول السابق يدل أن 27،14\% من الطلبة يفهمون جدا بمادة اللغة

العربية بالمنهج فضوءءالمنهجعلمستوى الوحدةالتعليمية ، و71،85\% منهم يفهمون قليلا فيها، وهذا يدل على أن معظم الطلبة يفهمون قليلا بمادة اللغة العربية بالمنهج فضوء المنهجعلمستوى الوحدة التعليمياة. 


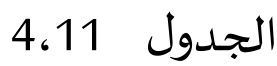

فرحة الطلبة بالطريقة التي استخدمها المدرسون

\begin{tabular}{|c|c|c|c|}
\hline النسبة المأوية & مجموع الأجوبة & احتمال الأجوبة & رقم \\
\hline$\% 14.28$ & 3 & أفرح جدا & أ \\
\hline \multirow[t]{2}{*}{$\% 85.71$} & 18 & أفرح قليلا & ب \\
\hline & - & لا أفرح & ج \\
\hline$\% 100$ & 21 & المجموع & \\
\hline
\end{tabular}

والجدول السـابق يدل أن 28،14\% من الطلبة يفرحون جدا بالطريقة التي

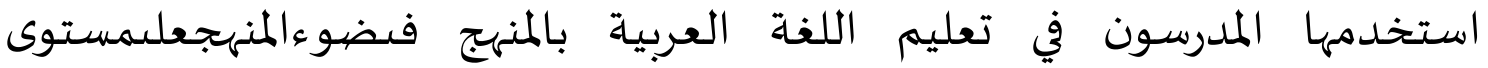
الوحدةالتعليمية ، و717،85\% منهم يفرحون قليلا . وهذا يدل على أن معظم الطلبة يفرحون قليلا بالطريقة التي استخدهها المدرسون في تعليم اللغة العربية.

$$
\text { الجدول 12، 12. }
$$

تكليف الطلبةة بالواجبات المنزلية في تعلم اللغة العربية بالمنهج فضيوءالمنهجعلمستوى الوحدةالتعليمية

\begin{tabular}{|c|c|c|c|}
\hline النسبـة المأويـة & مجموع الأجوبة & احتمال الأجوبة & رقم \\
\hline & - & يكلف كثيرا & أ \\
\hline$\% 76.19$ & 16 & يكلف قليلا & ب \\
\hline$\% 23.80$ & 5 & لا يكلف & ج \\
\hline$\% 100$ & 21 & المجموع & \\
\hline
\end{tabular}

والجدول السابق يدل أن 19،76\% من الطلبة يقولون أن المدرسين يكلفهم

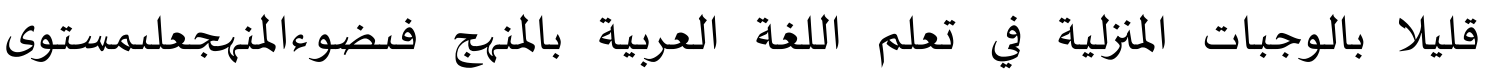
الوحدةالتعليمية ، 80،23\% من الطلبة يقولون إن المدرسين لا يكلفهم وهذا يدل 
على أن أكثر الطلبة يكلف قليلا في الوجبات المنزلية التي يكلفها المدرسون في تعلم اللغة العربية بالمنهج فضوءالمنهجعلبمستوى الوحدة التعليمية.

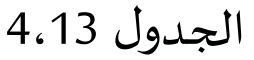

المحاولات التي يقوم بها المدرسون لترقية ترغيب الطلبة في القراءة

\begin{tabular}{|c|c|c|c|}
\hline النسبة المأوية & مجموع الأجوبة & احتمال الأجوبة & رقم \\
\hline$\% 19.04$ & 4 & بتكوين فرقة التعلم & i \\
\hline$\% 66.66$ & 14 & بتقديم المفردات & ب \\
\hline$\% 14.28$ & 3 & ممارسة القراءة & ج \\
\hline$\% 100$ & 21 & المجموع & \\
\hline
\end{tabular}

و الجدول السابق يدل أن 19،04\% من الطلبة يقولون إن المحاولات التي

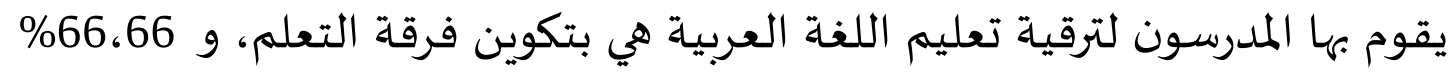

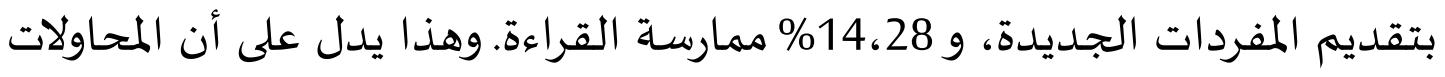
التي يقوم بها مدرسون لترقية تعليم القراءة بتكوين المفردات الجديدة.

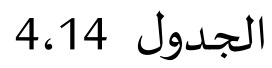

دافع الطلبة بالمحاولات التي يقوم بها المدرسون

\begin{tabular}{|c|c|c|c|}
\hline النسبة المأوية & مجموع الأجوبة & احتمال الأجوبة & رقم \\
\hline$\% 76.19$ & 16 & يدافع كثيرا & i \\
\hline$\% 19.04$ & 4 & يدافع قليلا & ب \\
\hline$\% 4.76$ & 1 & لا يدافع & ج \\
\hline$\% 100$ & 21 & المجموع & \\
\hline
\end{tabular}

والجدول السابق يدل أن 19،76\% من الطلبة يدافعون كثيرا بالمحاولات التي

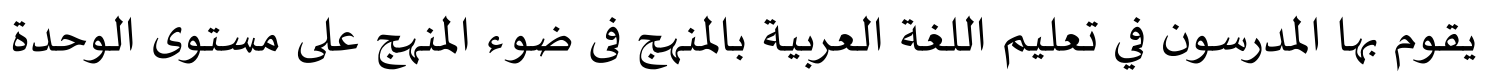


التعليمية ، 19،04\% من الطلبة يدافعون قليلاو 76، 4 \% لا يدافعون ، و هذا يدل

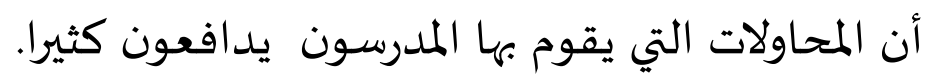

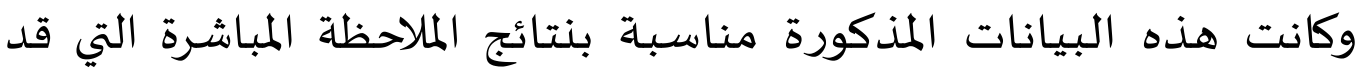

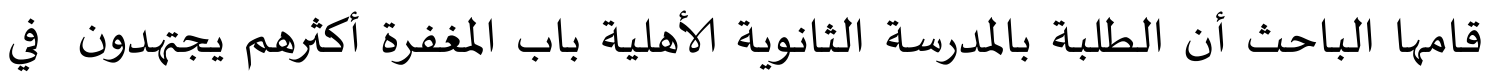

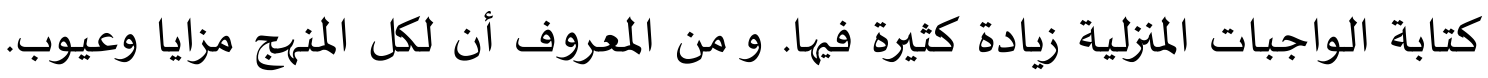

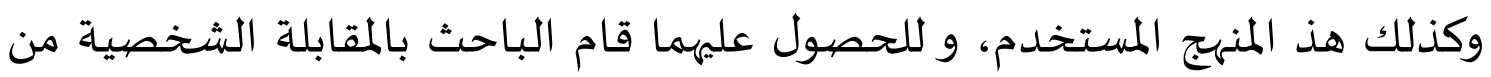
قبل مدرس اللغة العربية بهذه المدرسة. و بعدما يقوم الباحث بها فوجده نتمائج

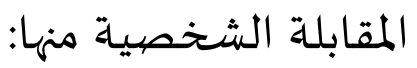
وأما المزيا من هذا المنهج فهي: 1. تشجيع تحقيق استقلالية المدارس في التعليم 2. تشجيع المعلمين على أن تصيح أكثر ابداعا في تنفيذ التعليم 3. مواد مواد تعليم اللغة العربية في ضوء المنهج على مستوى الوحدة التعليمية 4. والحد من عبء تعلم الطالب 5. الإعطاء الفرصة المدارس لتطوير المناهج لتناسب اختياجات المدرسة

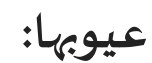

1. والافتقار إلى الموارد البشرية الذين هم قادرين على فهم مواد تعليم اللغة العربية في ضوء المنهج على مستوى الوحدة التعليمياة

2. عدم وجود رغبة من البنية التحتية التي تدعم تنفيذ مواد تعليم اللغة العربية في ضوء المنهج على مستوى الوحدة التعليمية

3. كثير من المعلمين لا يفهمون مواد تعليم اللغة العببية في ضوء المنهج على مستوى الوحدة التعليمية شامل 
اعتمادا على ما سبق من البيانات يستطيع الباحث أن يحقق جميع الفروض البرض

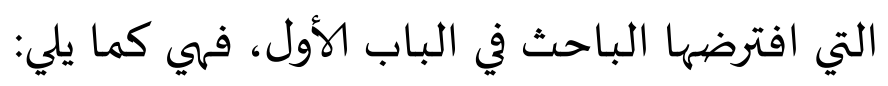

1) كانت تطوير تعليم اللغة العربية من ناحية المعرفة والوجدان والمهارات في

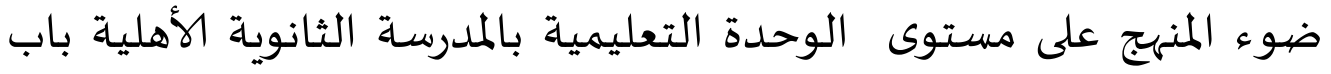
الممفرة لم تكن جيدا بعد جارت الباحث بمناقشة وتوزيع الإستبانة

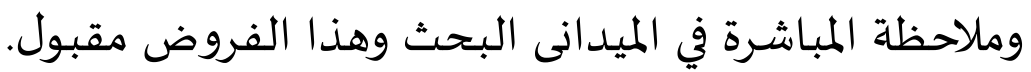

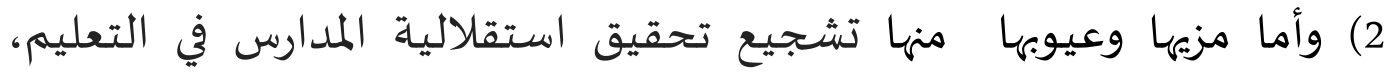

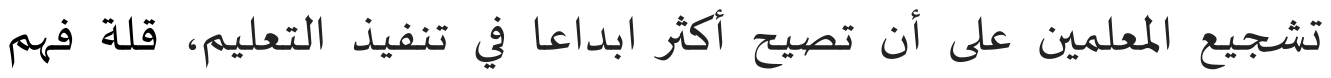
مدرس عن هذه الطريقة، هذ المنهج لم تكن منظم ويحتاج إلى إصلاحات

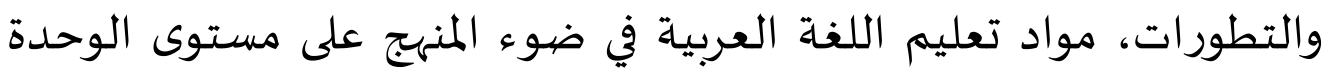

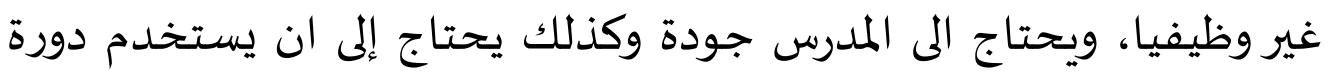
تدريبية لترقية جودة المدرس والطلبة وتطبيق مواد تعليم اللغة العربية في

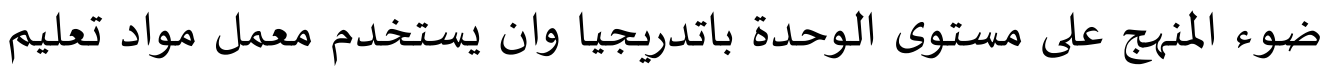
اللغة العربية في ضوء المنهج على مستوى الوحدة المنائ

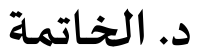

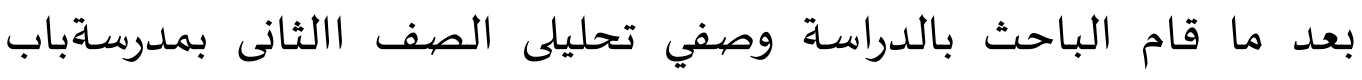
المففرة من البداية حتى الهاية وتحليل بياناتها، وبقي للباحث عرض الترائ النتائج

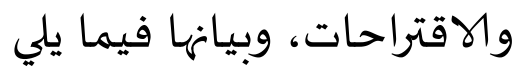

1- كان تتطوير تعليم اللغة العربية من ناحية المعرفة والوجدان والمهارا

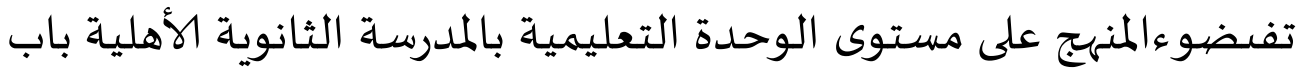
المففرة لم تكن جيدا بعد جارت الباحث بمناقشة وتوزيع الإستبانة

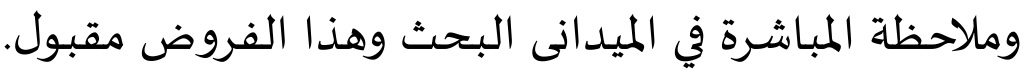

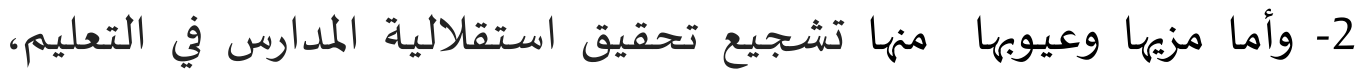

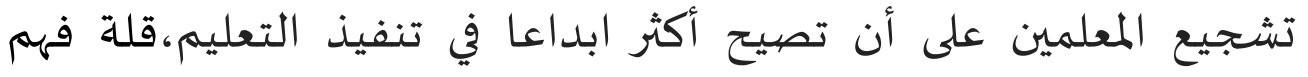
مدرس عن هذه الطريقة، هذ المنهج لم تكن منظم ويحتاج إلى إصلاحات المات الماتي

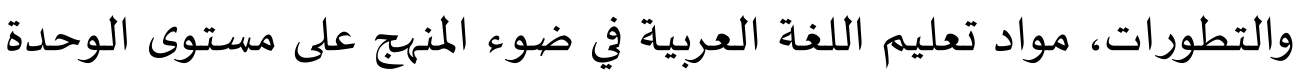


غير وظيفيا، ويحتاج الى المدرس جودة وكذلك يحتاج إلى ان يستخدم دورة

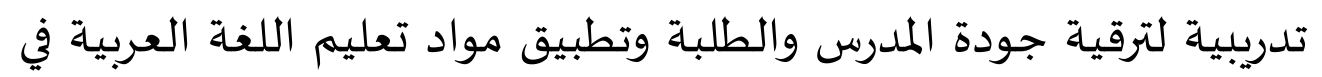

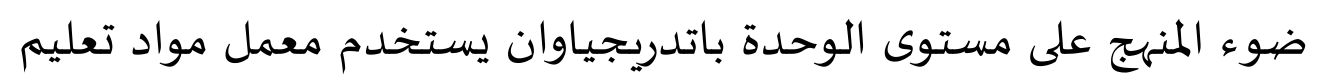
اللغة العربية في ضوء المنهج على مستوى الوحدة المداون

- مبراجع

دحية مسقان، استراتيجية تعليم اللغة العربية الفعال للناطقين بغيرها قراءة فى تجربة

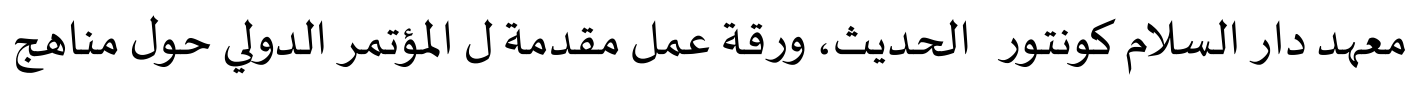

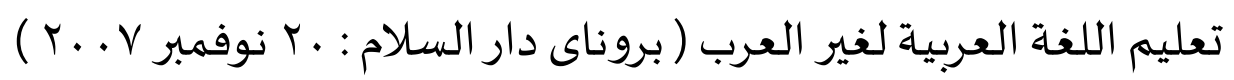

رشيد يوسف محمد عباس، الإطار العملي لبرامج تعليم اللغة العربية للناطقين بغيرها

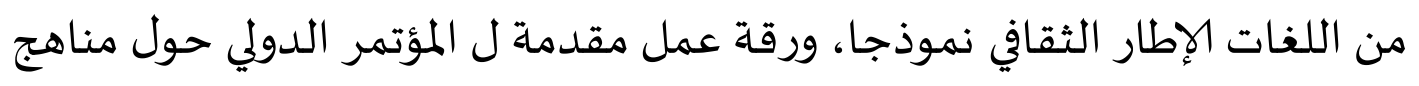

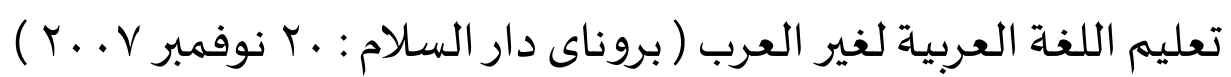

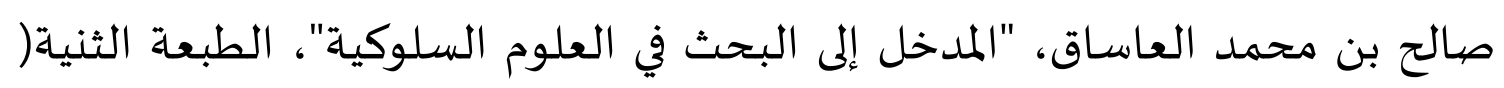
الرياض: مكتبة العبيكان، 2000) سهيل رزق دياب، مناهج البحث العلمي، (غزة فلسطين، 2003م) 